See Article page 319.

\section{Commentary: Demarcating the intersegmental fissure: Please cut along the dotted line}

\author{
Smita Sihag, MD, MPH
}

Anatomic segmental resection is a well-accepted therapy for clinical stage I lung cancers in patients with low pulmonary reserve or predominantly ground-glass tumors and has become increasingly popular with the refinement of minimally invasive techniques and adjunctive technologies. In terms of oncologic outcomes, some suggest equivalence to lobectomy for stage IA non-small cell lung cancers, although prospective data are still pending. ${ }^{1}$ In my own experience, the number of segmentectomies (as opposed to wedge resections or lobectomies) that I perform has easily doubled during the past year since transitioning to robotics, and the use of indocyanine green (ICG) has proven extremely easy and useful with the built-in infrared technology of the da Vinci Xi platform (Intuitive, Sunnyvale, Calif).

As Misaki and colleagues ${ }^{2}$ point out, a common method to identify the intersegmental fissure involves temporary reinflation of the lung after the segmental bronchus is clamped or divided, but we have all experienced the limitations and irritations of this maneuver. Emphysematous lungs may not inflate and subsequently deflate appropriately on command. As a result, the intersegmental fissure may remain ambiguous and worse yet, both operative domain and visualization are compromised. Resentment toward the anesthesiologist inevitably ensues, as what feels like an eternity passes while waiting for the lung to collapse again. And of course, stapling across a partially inflated lung will almost certainly result in postoperative air leak.

\footnotetext{
From the Thoracic Service, Department of Surgery, Memorial Sloan-Kettering Cancer Center, New York, NY.

Disclosures: The author reported no conflicts of interest.

The Journal policy requires editors and reviewers to disclose conflicts of interest and to decline handling or reviewing manuscripts for which they may have a conflict of interest. The editors and reviewers of this article have no conflicts of interest.

Received for publication May 5, 2020; revisions received May 5, 2020; accepted for publication May 8, 2020; available ahead of print May 14, 2020.

Address for reprints: Smita Sihag, MD, MPH, Thoracic Service, Department of Surgery, Memorial Sloan-Kettering Cancer Center, 1275 York Ave, C-881, New York, NY 10065 (E-mail: sihags@mskcc.org).

JTCVS Techniques 2020;3:327-8

2666-2507

Copyright (C) 2020 The Authors. Published by Elsevier Inc. on behalf of The American Association for Thoracic Surgery. This is an open access article under the CC BY-NCND license (http://creativecommons.org/licenses/by-nc-nd/4.0/).

https://doi.org/10.1016/j.xjtc.2020.05.003
}

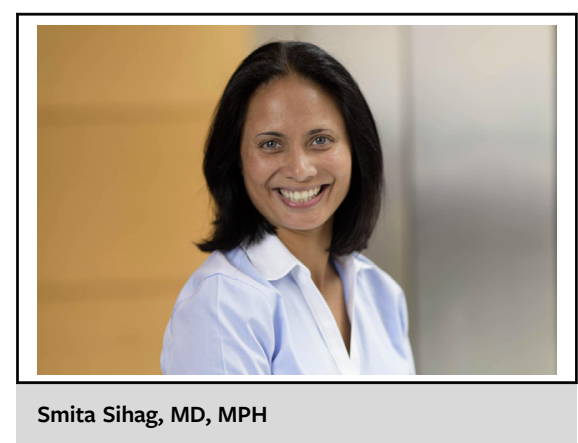

CENTRAL MESSAGE

The authors demonstrate that a constant-rate infusion of indocyanine green leads to more consistent, longer lasting, and higher maximum fluorescence intensity when demarcating an intersegmental fissure compared with bolus administration.

Misaki and colleagues ${ }^{2}$ were among the first to describe the use of intravenous injection of ICG and an infrared camera to identify the intersegmental fissure according to perfusion once the segmental pulmonary artery is divided. The authors published this pilot study of 8 patients using rapid injection of a $3.0 \mathrm{mg} / \mathrm{kg}$ ICG bolus with reasonable safety and efficacy in $2010 .^{2}$ Subsequent studies have confirmed the utility and generalizability, as well as the possible optimization of oncologic margin, with this methodology. ${ }^{3,4}$ However, this approach is not perfect, and the authors aptly note that there are cases in which the demarcation line appears mottled or the ICG washes out too quickly. Ideally, the intersegmental demarcation is visible for enough time to allow marking a dotted line with electrocautery.

In their current article, Misaki and colleagues ${ }^{5}$ expand on their previous work to compare bolus (similar dosing as above) versus constant-rate infusion of ICG to identify the intersegmental fissure during thoracoscopic segmentectomy. ${ }^{5}$ Their findings demonstrate more consistent, longer lasting, and higher maximum fluorescence intensity with a constant rate infusion at $300 \mathrm{~mL} / \mathrm{h}$ of $2.5 \mathrm{mg} / \mathrm{mL}$ ICG solution. Accordingly, the intersegmental fissure was well demarcated in 9 out of 10 thoracoscopic segmentectomies in the constant-rate infusion group, compared with only 3 out of 10 in the bolus group. The sample size is small and only 3 out of 10 in the bolus group seems low, but, overall, 
this is a very straightforward study that offers a simple solution to a technical problem. It is exactly these types of pilot studies and clinical trials that are much needed in our specialty to help us enhance intraoperative decision making, streamline procedures, and overcome challenges, no matter how seemingly trivial.

\section{References}

1. Chan EG, Chan PG, Mazur SN, Normolle DP, Luketich JD, Landreneau RJ, et al. Outcomes with segmentectomy versus lobectomy in patients with clinical T1c NO M0 non-small cell lung cancer. J Thorac Cardiovasc Surg. March 23, 2020 [Epub ahead of print].
2. Misaki N, Chang SS, Igai H, Tarumi S, Gotoh M, Yokomise H. New clinically applicable method for visualizing adjacent lung segments using an infrared thoracoscopy system. J Thorac Cardiovasc Surg. 2010;140:752-6.

3. Pardolesi A, Veronesi G, Solli P, Spaggiari L. Use of indocyanine green to facilitate intersegmental plane identification during robotic anatomic segmentectomy. $J$ Thorac Cardiovasc Surg. 2014;148:737-8.

4. Mehta M, Patel YS, Yasufuku K, Waddell TK, Shargall Y, Fahim C, et al. Nearinfrared mapping with indocyanine green is associated with an increase in oncological margin length in minimally invasive segmentectomy. J Thorac Cardiovasc Surg. 2019;157:2029-35.

5. Misaki N, Tatakawa K, Chang SS, Go T, Yokomise H. Constant-rate intravenous infusion of indocyanine green leading to high fluorescence intensity in infrared thoracoscopic segmentectomy. J Thorac Cardiovasc Surg Tech. 2020;3:319-24. 